\title{
A Cloud Associated Smart Grid Admin Dashboard
}

\author{
P. Naveen \\ Faculty of Engineering and Science \\ Curtin University \\ Miri, Sarawak, Malaysia \\ navp80@gmail.com
}

\author{
Wong Kiing Ing \\ Faculty of Engineering and Science \\ Curtin University \\ Miri, Sarawak, Malaysia
}

\author{
Michael Kobina Danquah \\ Faculty of Engineering and Science \\ Curtin University \\ Miri, Sarawak, Malaysia
}

\author{
Amandeep S. Sidhu \\ Faculty of Engineering and Science \\ Curtin University \\ Miri, Sarawak, Malaysia
}

\author{
A. Abu-Siada \\ Department of Electrical and Computing Engineering \\ Curtin University \\ Perth, Australia
}

\begin{abstract}
Intelligent smart grid system undertakes electricity demand in a sustainable, reliable, economical and environmentally friendly manner. As smart grid involves, it has the liability of meeting the changing consumer needs on the dayto-day basis. Modern energy consumers like to vivaciously regulate their consumption patterns more competently and intelligently than current provided ways. To fulfill the consumers' needs, smart meters and sensors make the grid infrastructure more efficient and resilient in energy data collection and management even with the ever-changing renewable power generation. Though cloud acts as an outlet for the energy consumers to retrieve energy data from the grid, the information systems available are technically constrained and not user-friendly. Hence, a simple technology enabled utilityconsumer interactive information system in the form of a dashboard is presented to cater the electric consumer needs.
\end{abstract}

Keywords-admin dashboard; cloud; smart grid

\section{INTRODUCTION}

Electrical energy has progressed as a vital part of modernday life. The major portion of the energy produced comes from fossil-fueled power stations and the rest from atomic and renewable energy sources. Due to rapid industrialization, urbanization, cultural changes and modern human lifestyle, the electrical energy demand has increased exponentially and it becomes a challenging task to the electric energy providers and distributors. Particularly, the peak power demand management is one of the principal concerns even though it lasts for a short period of a day [1-3]. This management task involves a high marginal cost to maintain the fast responding (fossil-fuelled) standby power plants. Besides, additional costs are involved in overcoming the environmental issues caused by the standby units. Peak demand charges can be often more than 30 percent of an industrial consumer's monthly utility bill $[4,5]$. The electric consumption charges are based on the highest capacity desired for the duration of the billing period, normally, a 15minute interval through that billing cycle. Due to advancement in real-time monitoring systems, energy usage can be easily monitored, hence energy demand peaks become more obvious.
Inappropriately automated building management systems and mechanical system letdowns are collective causes of higher than required energy peaks.

The prime share of the energy production cost is the fuel cost for fossil-fuelled power plants; hence, the frequent escalation of the fuel cost is a risk for investors on achieving the return on their investments $[5,6]$. Utilities suffer from limited/uncertain fuel supplies and cash collection from the government and energy sector. Moreover, the availability of intermittent forms of renewable generation, storage, and backup issues, the unattractive energy buyback policies and energy cost, and their high capital investment with limited funding resources are further challenges in terms of higher energy cost. The energy consumers are not satisfied with the high-energy cost, supply interruptions, and impact to environment. A change in the energy systems was inevitable and thus smart grid came into existence [7-10]. Energy management is the usual technique of monitoring, controlling, and conserving energy [11], whereas, in smart grid, energy management is the foremost concern. It is crucial for resource conservation, environmental protection and economic considerations without conceding functional processes by optimally coordinating many energy sources. To gain benefits through energy management, the smart grid (SG) energy management system (EMS) integrates building energy management system (BEMS), demand side management (DSM), home energy management (HEM), and demand response (DR). BEMS is a classy technique envisioned to monitor and control building services like heating, ventilation, and air conditioning (HVAC), lighting or security measures, ensuring the building operates at maximum efficiency by avoiding energy wastage. It will adjust electrical load automatically according to the demand response events communicated by the energy provider [12]. DSM signifies the development, executing, and monitoring activities of electric utilities, which are premeditated to reassure consumers to amend their quantity and pattern of electricity usage. As a result, the utility gets to benefit from the shifting of energy consumption from peak to non-peak hours. DSM programs 
[13] inspire the end-user to be energy efficient through lighting retrofits, building automation advancements, HVAC enhancements, variable frequency drives, etc. DSM is essential in SG to maintain grid stability and to integrate new sources of energy generation for capacity addition and environmental friendliness. HEM is a technology platform [14] that permits the end-user to monitor energy consumption and generation and to physically regulate and/or automate the use of energy within a home. HEM Systems provide information to end-users about how they use energy in their premises and/or alert them remotely via a smartphone or web service or based on a set of rules, which can be planned or augmented based on end-user behavior. DR is a significant demand-side management technique. It encourages end-users $[12,15]$ to carry out shortterm reductions in their energy use in response to (i) a price signal from the electricity hourly market, or (ii) an incentivebased trigger initiated by the grid administration.

The evolved SG system accomplishes electricity demand in a sustainable, dependable and economical manner. It involves all kinds of electric power generating resources ranging from conventional to all types of renewable energy sources and residential, commercial and industrial electric consumers. Renewable energy resources being practiced successfully like solar are weather dependent and the power generation varies continually, hence the power generation must frequently adjust to match supply against demand. Henceforth, heaps of sensors and smart meters are being employed [16-18]. These incorporated sensors produce a huge amount of data instantaneously, which are gathered, and processed in order to produce control decision to progress efficiency and reliability of the power grid. To manage the masses of sensors and smart meters electric utilities need to comprehend the bilateral messaging network management system to a distributed data center [19]. In this respect, cloud computing is envisioned to perform significant tasks in the modernization process of the existing SG. Cloud computing is an evolving expertise for empowering trustworthy and necessity-based access to various computing sources, which can rapidly provide an economical way to the service providers $[20,21]$. It offers new-fangled openings to the ICT industry permitting businesses to contract out their IT services to cloud providers and circumvent costly open investments of launching their own infrastructure and subsequent costs of maintenance and upgrades [22, 23]. It is evident that cloud computing forms a bridge between the $\mathrm{SG}$ and the energy consumers. The information systems available to consumers are technically constrained. Moreover, such resources are limited in quantity and not user-friendly to all consumers. Hence, a simple technology enabled utilityconsumer interactive information system is preferable to cater the needs of the electric consumers.

\section{RELATED RESEARCH WORK}

The greatest challenge to an up-and-coming SG lies in engaging consumer support. Without it, the SG cannot be existent and it cannot provide its assured benefits. Eventually, the consumer is paying for the SG, which on one hand does yield imperative benefits for consumers, but on the other, they come at a substantial cost and, at the individual level, the need for these benefits may feel immediate. The German smart grid developed smart meter gateway (SMGW) to speed up the processing of data acquisition, energy consumption monitoring, supply-demand management, and secured communication between energy consumers and external bodies [24]. The SMGW is not a hardware, but it has a built-in hardware security module for protecting the important materials and cryptographic operations. The SMGW administrator plays the technical role of configuring tariffing profiles, issuing and controlling SMGW certificates, and embedded firmware updates to regulate the tasks of various hardware devices and systems, but he cannot access to the end-users' energy consumption data. The extension of SMGW to household becomes a major concern for all residential consumers and the associated cost of the maintenance and up keeping of the gateway.

The smart grid administration of European R\&D smart grid projects is facing challenges in the administration and handling of user rights. DISCERN [25] offers an expressive web-based tool concept with the objective of re-using SG data from both field trials and simulations by (European) SG projects, expediting the reuse of prevailing SG solutions, associating the present and upcoming SG projects and, thus, facilitating the assimilation of real-world trials and simulations. The dashboard primarily focuses on the user access rights to handle data as well as historical data in the context of information security management systems. The comprehensive SG dashboard system facilitates a user to upload and store a data object in the dashboard. The user can retrieve the stored data and can transfer to third parties. The dashboard has messaging options and data analyzing facilities. Since the dashboard has multitasking amenities, it has room for rear-enders in the SG dashboard system when more than one user with write or manage rights want to edit the same data object at the same time. The SG dashboard system should be able to manage multi-editing of the data objects. The Gujarat State Government in India has initiated a SG dashboard concept for its consumer's convenience in 2013 [26]. It facilitates its consumers to participate in various programs such as demand side management and energy cost forecast. This helps the planning of their energy-related activities based on the tariff forecast in an economical way. The dashboard sends real-time messages to alert them about their energy consumption trends, planned supply interruptions, past energy consumption statistics, monthly energy consumption bills etc. The security and reliability of the dashboard were not yet ascertained and the consumers' feedback on the usage of the dashboard would justify its suitability at a large scale. In Ireland and Northern Ireland, EirGrid plc [27] gets involved in electric energyrelated activities such as transmission, distribution and marketing. To enhance its services, EirGrid group developed a web-based smart grid dashboard. It empowers the users to outlook and parallel the power system information and graphs in one location. In addition, the users can visualize the realtime energy data with the time-varying energy cost. It is userfriendly and has no need for $\log$ in because the information provided is general and not user specific.

This paper presents a cloud-based SG admin dashboard that provides real-time data of the SG for the benefit of the utilities, renewable energy investors, independent power producers, and 
end-users for their energy-related activities and suitable actions. While designing the dashboard, equal importance was given to the electric utility and the consumer.

\section{CLOUD FOR SMART GRID MANAGEMENT}

Smart Grid encompasses conventional power plants such as thermal power stations (coal, oil, and gas, etc.) and renewable energy sources. It forms a hybrid combination of both conventional and renewable energy sources to achieve economic as well as environmental benefits. The power generated has been delivered to the consumers through long transmission and distribution networks. All the data will be stored and updated periodically by the electric utility data management system (i.e. in every 20 minutes) and simultaneously passed on to the cloud network. Since SG has the two-way communication facility, the utilities and cloud network are connected on real-time web services for the exchange of information. It is worth noticing that there is no power flow between the utilities and the cloud. Instead, the power flow is only from the utilities to the consumers (endusers). A rudimentary formation of SG and cloud architecture has been presented in [28, 29], and based on that work, a modified SG and cloud architecture has been proposed as shown in Figure 1.
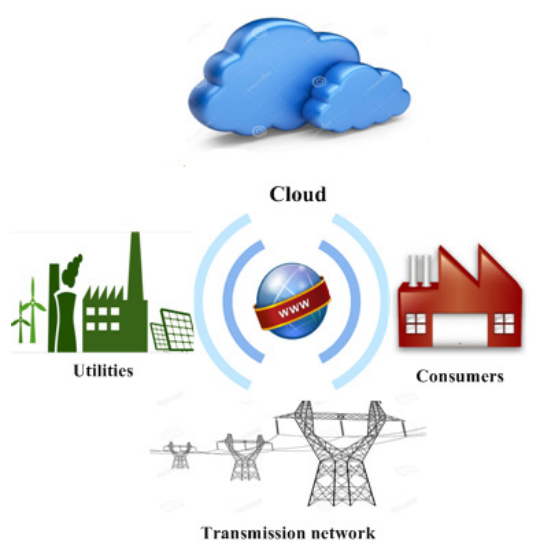

Fig. 1. Proposed smart grid and cloud architecture

\section{A. The Electric Consumers (End-Users)}

The chief groupings of electric consumers are of industrial, commercial and residential type. They are interconnected with utilities through smart meters and intelligent sensors. These smart meters measure the energy consumption at their end and communicate with the sensors. The incorporated sensors produce a mass of data instantaneously and they take control decisions in order to improve efficiency and consistency of the power grid. From the smart meters' and sensors' communications, the total energy consumption scaled load demand (power demand) is determined. The consumers' expectation is the availability of electric supply as and when they need it. Through the cloud network services, consumers can schedule their power requirement well in advance since they are informed far ahead about the availability of electric supply, the probable electricity unit cost, the power supply's planned shut-down, the probable outages due to weather conditions, system faults, and blackout due to threats.

\section{B. The Cloud Network}

This is a rather recent and advanced addition in SG to enhance its performance. It is a junction for the communication flow between the utilities and the consumers. SG communications networks are used to observe the load variations, power generations, weather forecast, consumers' expectations, security threats, etc. to optimize the real-time functioning of the system and envisage faults prior to their occurrence $[28,29]$. Cloud computing platforms provide the possibility to exploit huge amounts of resources, both in terms of data storage and in the capability of flexible and scalable data processing.

\section{Dashboard}

The cloud-based smart grid system needs to have the capability to monitor electrical power consumption in $\mathrm{kWh}$, unit energy costs, weather conditions, renewable energy generation etc. In deregulated power market, there should be provision for end-users to participate in market transactions and to optimize their energy consumption and energy cost, and to avail environmental credit wherever possible. End-users can be encouraged by power market price signals for decision-making and intermingle with power generation companies and the power grid. To accommodate certain features as discussed, a web-based user-friendly dashboard is presented in the next section.

\section{DATA ACQUISITION NETWORK}

The SG data are obtained from the system technical network support as:

- All energy resources, backup storage systems and all load points (industrial, commercial and residential) are connected to sensors, preferably wireless. These sensors aid higher precision of inflow predicting, the actual energy consumption by the end-users and the load forecast.

- These sensors are then connected to controllers for monitoring. Data from the sensors are inputs and are handled and related to the rules and settings prescribed by the administrator. If the input data is within an acceptable range, then it will be passed on to the $\mathrm{SG}$ admin dashboard through modems. Data outside an acceptable range trigger the control system to issue commands to change the status of the controlled device.

- The data communication to SG admin can be done through LAN, WAN, CAN, HAN or satellite communication depending upon the SG structure.

- All collected data are stored in the cloud server, and are retrievable.

- The SG admin can control the ON and OFF status of the DER or RE sources on the consumer side. If any alert on instability in SG operation occurs, the administrator can 
switch OFF or isolate the source to maintain the stable operation.

\section{SMART GRID ADMIN DASHBOARD}

A web-based smart grid admin dashboard (SGAD) has been developed for administrative purposes and for the planning of consumer energy-related activities. The proposed dashboard involves cloud for data storage and exchange of information. ThecCloud has generally three models: Infrastructure as a Service (IaaS), Platform as a Service (PaaS), and Software as a Service (SaaS). PaaS as a service model offers computing platforms that classically contain operating systems, programming language execution environment, database, and web server. It is the second layer on top of IaaS. Windows Azure, Google App Engine, and Apache Stratus are some common examples of PaaS. PaaS is preferred for the Smart Grid services because of its technical suitability and flexibility.

The dashboard of the SG system is presented in pictorial form. The Homepage for the $\mathrm{SG}$ system has the main navigation panel and its options as seen in Figure 2. The SGAD-visualizer (Figure 3) facilitates the registered operators (both administrators and end-users) to monitor the existing data of the SG system by providing the IP address, start date or time, and end date or time. There are two categories of IP addresses: one for the system admin and the other for the endusers. The system admin can control, monitor, and manipulate the data of all end-users, whereas the end-user is entitled to visualize the information and data relevant to him/her only. The visualizer has three display options: two options in tabular format (online monitor tabular and data tabular) and the other in graphical format dashboard).

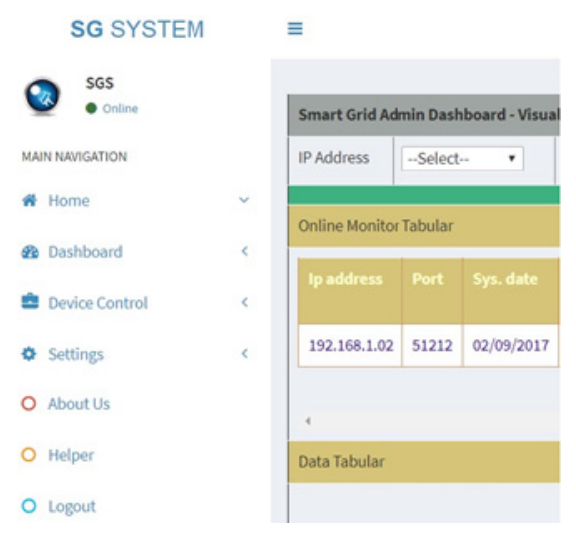

Fig. 2. A portion of the Home page

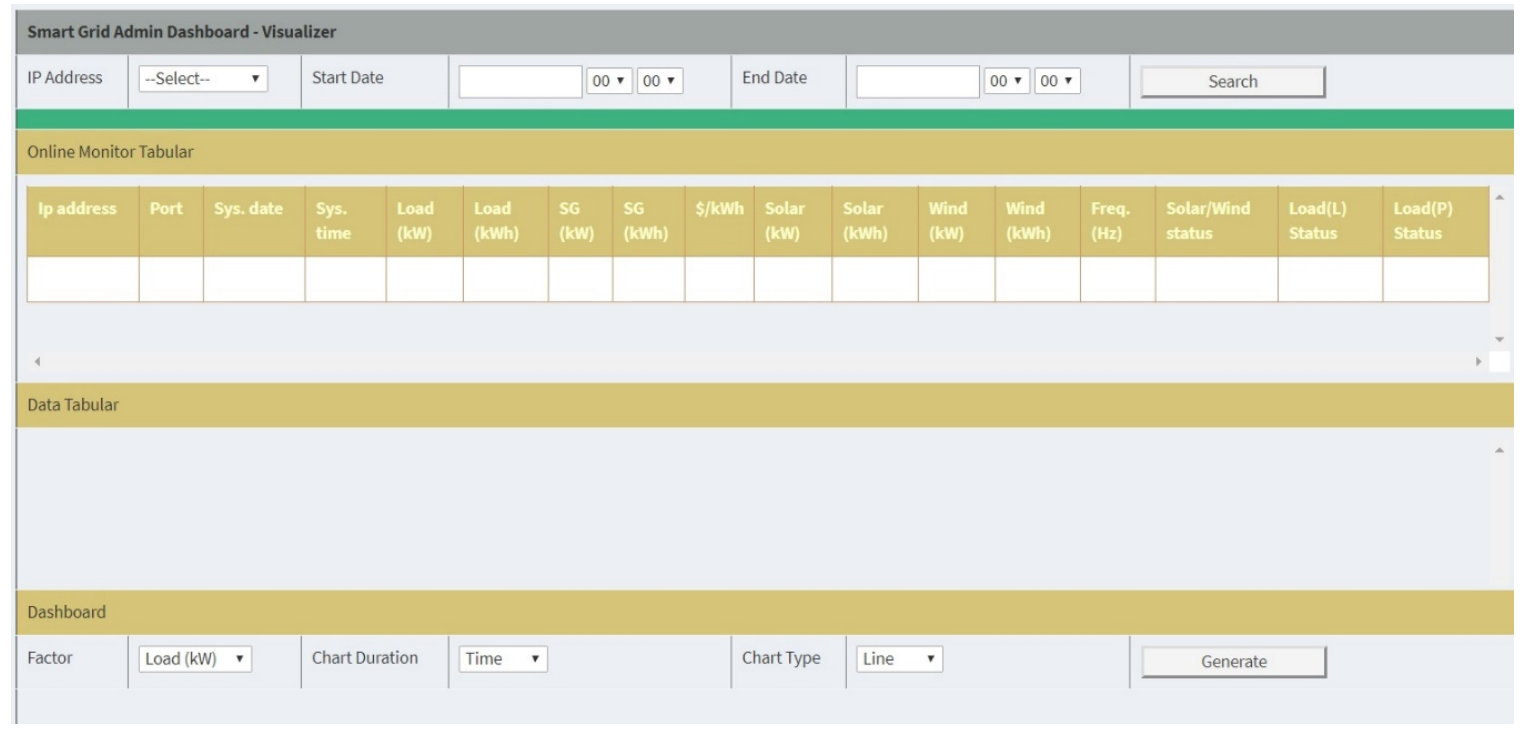

Fig. 3. Smart grid admin dashboard-visualizer

The data visualized through the Online Monitor Tabular and the Data Tabular are shown in Table I.

\section{- The Online Monitor Tabular}

Once the admin logs in, the online monitor tabular displays the latest data of the SG system. The information is meant for the administration purpose only, and not visible to the end-user.

\section{- Data Tabular}

\section{a) For system admin}

If no search option is chosen, the data tabular displays all the data available in the SG system. If IP address option is chosen, it displays the data relevant to that IP address available in the SG. If start/end date or time options are chosen, it displays the relevant data available in the SG.

\section{b) For end-user}

If no search option is chosen, the data tabular displays all the data available in the SG system relevant to his/her IP address. If start/end date or time options are chosen, it displays the corresponding IP address relevant data. The end-user does not have the privilege of visualizing other end-users' information. 


\section{- Dashboard for Graphical Display}

The dashboard has three components and they are provided with additional sub-components. The admin or the end-user can select any one of the sub-components from the Factor component as presented in Figure 4. The sub-components vary from the system demand, the system generation, the unit cost of energy, the solar and wind power generation (by the end-users), the system frequency and the lighting and power loads of the end-users. The dashboard provides a special option to save the retrieved information for the end-user reference in later days without $\log$ in again. The next component is the Chart Duration and it has the options for viewing the data from a day to year as seen in Figure 5. There are options namely line chart and column chart in the Chart Type component as in Figure 6. The line chart is preferable to compare changes over the same period for more than one data group. Column charts are ideal to compare stuff between different data groups or to track changes over time (day, week, month, and annual).
TABLE I. VISULAIZED DATA

\begin{tabular}{|c|c|}
\hline SG load data & Load demand $(\mathrm{kW})$ \\
\hline \multicolumn{2}{|c|}{ Energy consumption (kWh) } \\
\hline \multirow[t]{3}{*}{ SG generation data } & Power generation $(\mathrm{kW})$ \\
\hline & Energy produced (kWh) \\
\hline & System frequency $(\mathrm{Hz})$ \\
\hline \multicolumn{2}{|c|}{ Unit energy cost $(\$ / \mathrm{kWh})$} \\
\hline \multirow{2}{*}{ Solar power data } & Power generation $(\mathrm{kW})$ \\
\hline & Energy produced (kWh) \\
\hline \multirow[t]{2}{*}{ Wind power data } & Power generation $(\mathrm{kW})$ \\
\hline & Energy produced (kWh) \\
\hline \multirow{2}{*}{ Consumer load status } & Lighting load (ON/OFF) \\
\hline & Power load (ON/OFF) \\
\hline
\end{tabular}

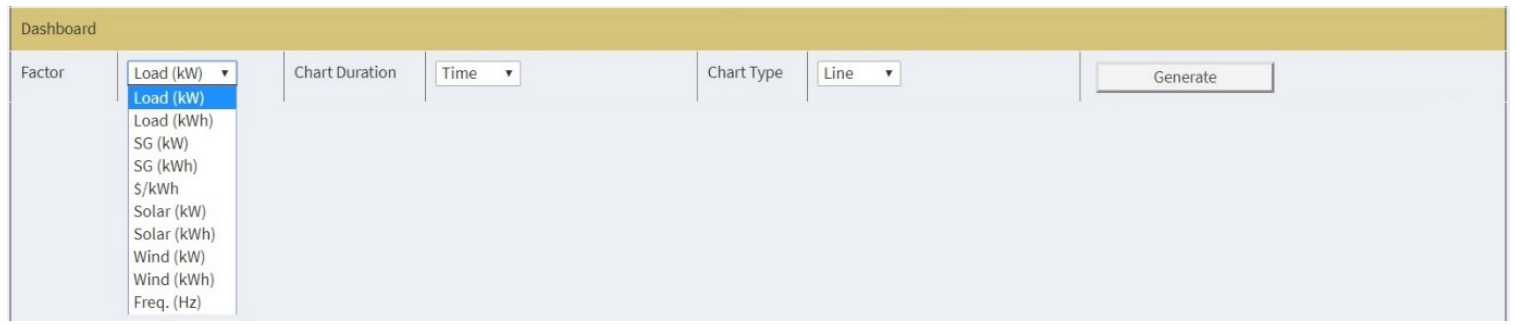

Fig. 4. Factor sub-components

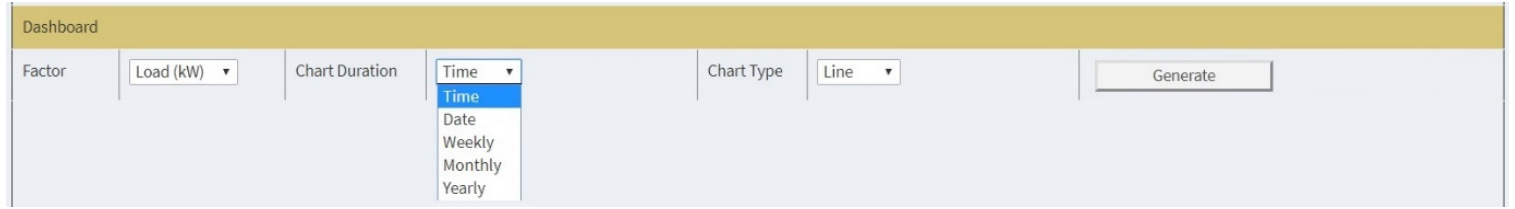

Fig. 5. Chart duration sub-components

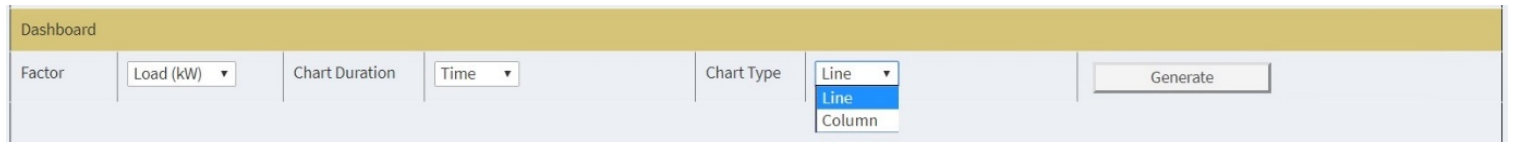

Fig. 6. Chart type sub-components

\section{SGAD DISPLAYS}

Though several options are provided in the SGAD for the admin's and end-users' data retrieval and visualization, only a few displays are presented here, and the data retrieval and visualization through other options follow the same operation logic. When the admin logs in, the latest data entry from the SG system will be displayed as in Figure 7. This information is not visible to any end-users. The entry of an end-user IP address by the system admin displays the relevant data of that user as well as the latest system data (Figure 8). If the system admin wants to visualize the entire energy-related activities of all the endusers on a specific date, it is possible by entering the date of interest on the start date. A portion of the data for few endusers on September 2, 2017 s presented in Figure 9.
The end-user can monitor his/her energy activities on a day during different timings by providing the date and duration. Figure 10 shows the energy activities of the end-user with IP address 192.168.1.220 on march 19, 2016 during the time 01:17:21 - 01:18:16. End-users want to know the unit energy cost to regulate their energy consumption and to plan for their future demand in a cost-effective manner. The user can select the sub-component - unit energy cost, $\$ / \mathrm{kWh}$ option from the factor component as presented in Figure 4. The dashboard provides the relevant information for the end-user as seen in Figures 11 (a) (line chart) and 11 (b) (bar chart).

Consumers having their own renewable energy sources like the wind and/or solar power can plan their energy usage according to their own power generation, and their excess 
power can be exported to the grid. The dashboard supports them to participate in load shedding and load shifting solutions, and to shift among several competing energy providers based on greenhouse gas emissions or social goals. The dashboard has the option of visualizing their import and export nature of energy by $\mathrm{ON}$ and OFF controls as seen in Figure 9. It can also display the unit energy cost variations during a period as in Figures 11 (a) and (b). The SG admin can control the ON /
OFF status of the DER or RE sources on the end-user side. If any alert on instability occurs the administrator can switch OFF or isolate the source to maintain stability. These dashboard displays are on a real-time basis providing energy-related activities in a user-friendly way. The system admin can practice the dashboard to identify system performance matters, and the end-users to optimize their energy consumption in a costeffective manner.

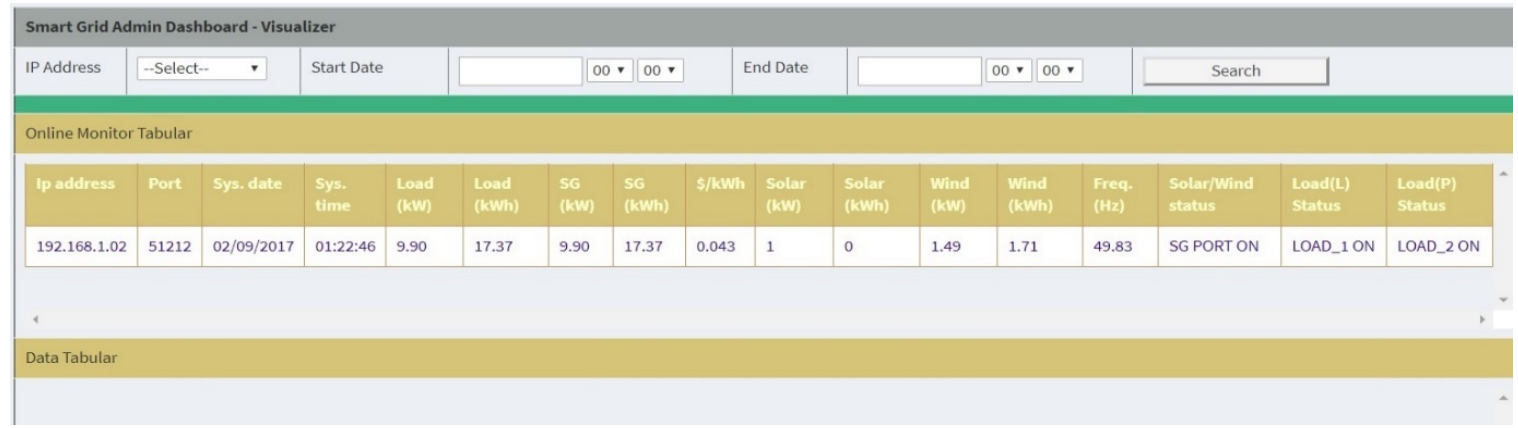

Fig. 7. Latest data visualization by admin

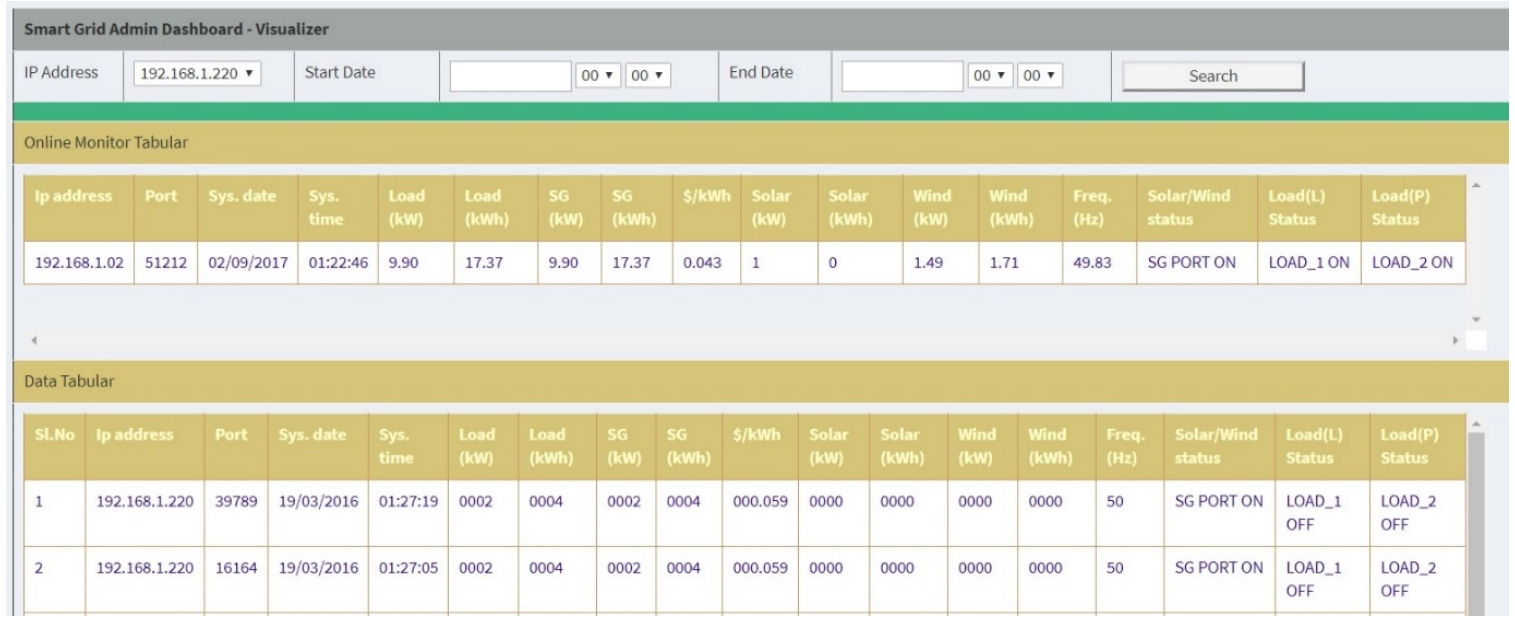

Fig. 8. Data visualization by IP address

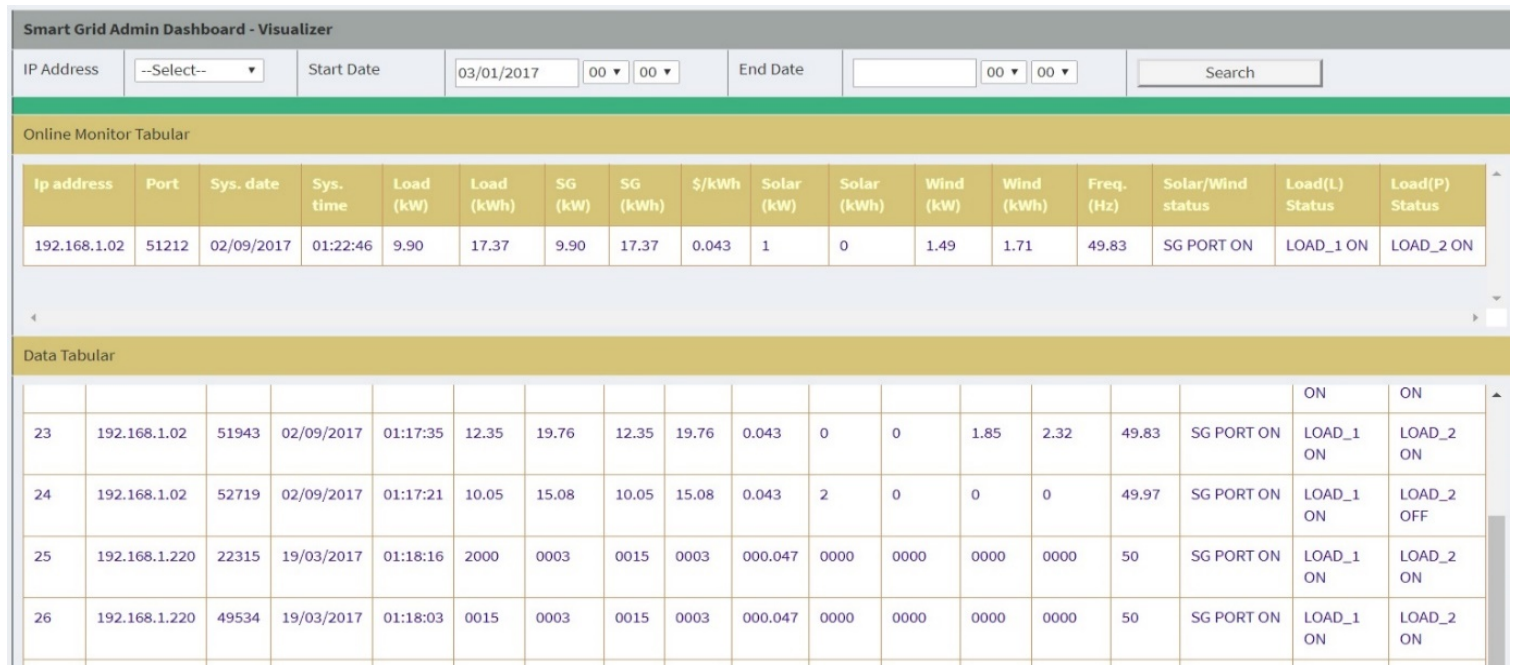

Fig. 9. Data visualization of many end-users 


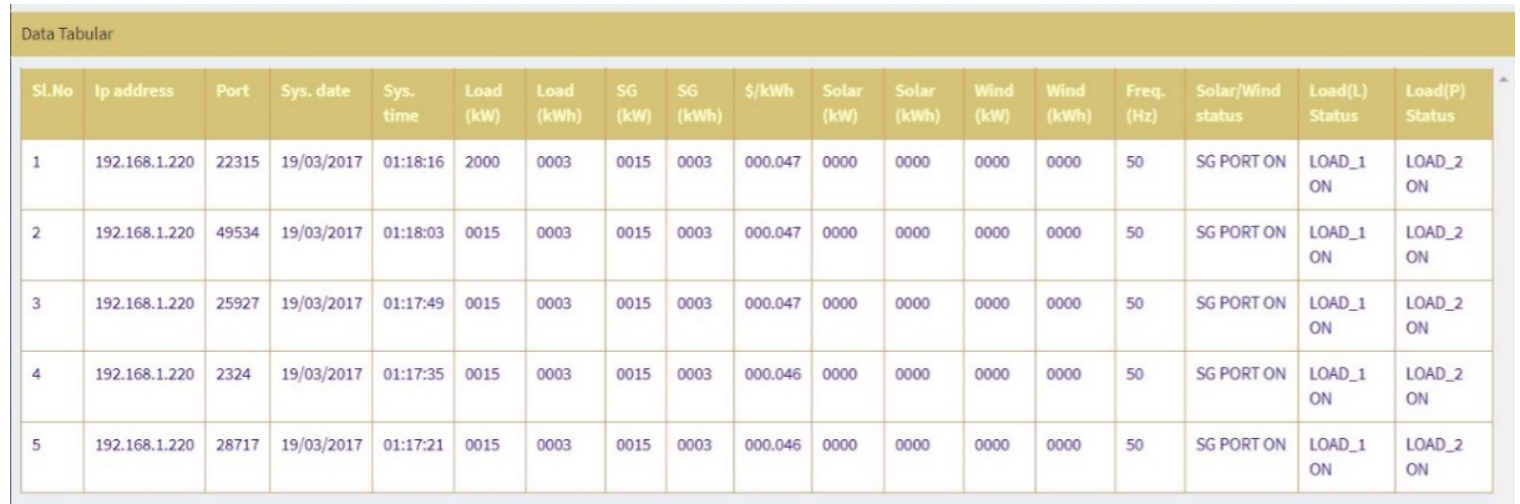

Fig. 10. Data visualization by an end-user

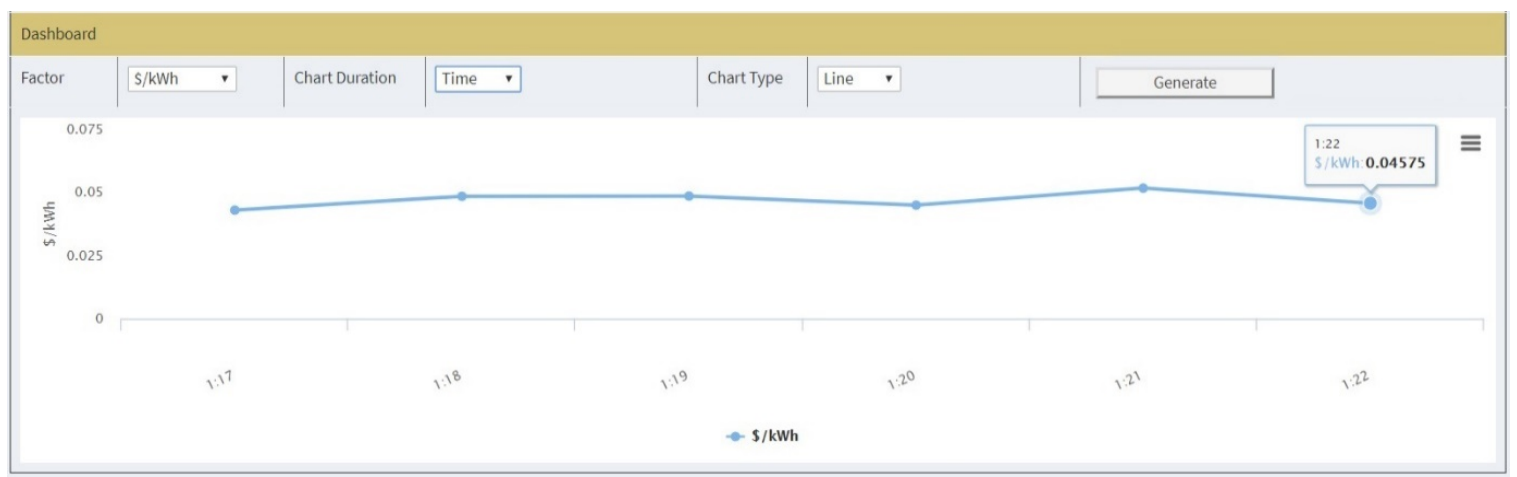

(a)

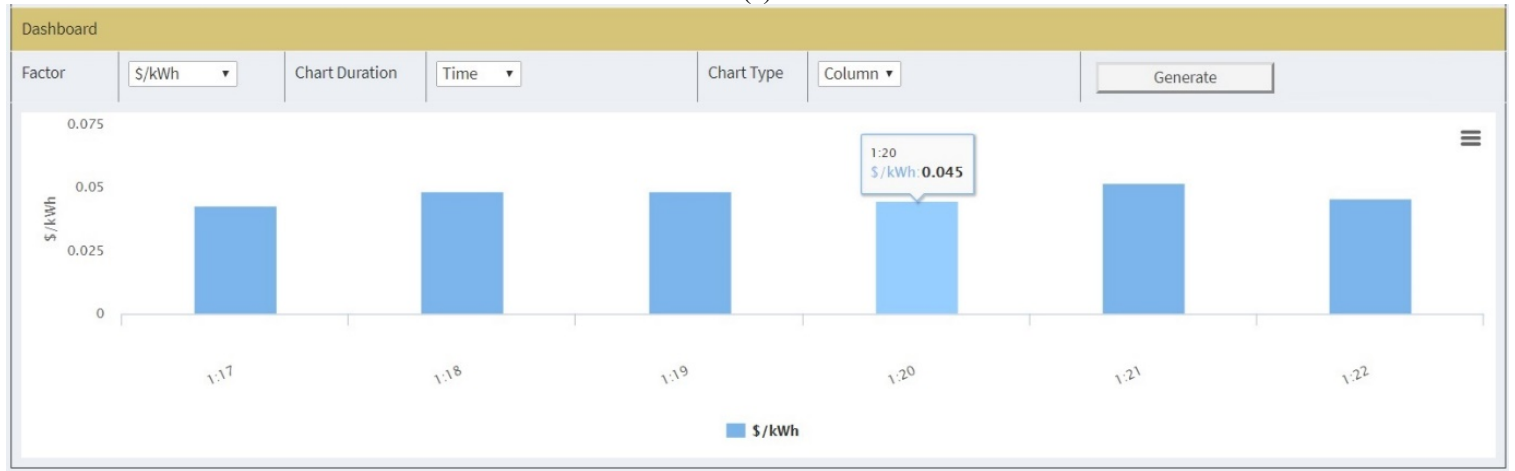

(b)

Fig. 1. Unit energy cost visualization: (a) Line chart, (b) Column chart

\section{SUPERIORITY OF THE PROPOSED DASHBOARD}

It is significant to compare the performance of the proposed dashboard against the earlier discussed dashboards [24-27]. The primary objective of the German SG developed smart meter gateway (SMGW) is to speed up the processing of data acquisition, energy consumption monitoring, supply-demand management, and secured communication between energy consumers and external bodies [24]. Here, the end-user has limited scope for interaction with the SMGW administrator. In addition, the extension of SMGW to household becomes a major concern for all residential consumers along with the associated cost of the maintenance and up keeping of the gateway. Whereas the proposed dashboard is user specific, and all types of registered end-users such as residential, industrial, and commercial can make use of the dashboard.

The dashboard in [25] focuses on the user access rights to handle data as well as historical data in the context. It facilitates the users to upload and store a data object in the dashboard. The users can repossess the stored data and can transfer to third parties. The dashboard has multi-tasking amenities, however, it has room for data trafficking in the system when more than one user with write or manage rights want to edit the same data object at the same time. The SG dashboard system should be able to manage multi-editing of the data objects, and the data traffic congestion should be reduced. The proposed SGAD has no such restriction on the number of registered users, and the data can be stored and retrieved without any such data trafficking. Cloud computing platforms provide the possibility 
to exploit huge amounts of resources, both in terms of data storage and processing. The SG dashboard in [26] enables its consumers to participate in several programs such as demand side management and energy cost forecast. This supports to plan their energy-related activities based on the tariff forecast in an economical way. The dashboard sends real-time messages to alert them about their energy consumption trends, planned supply interruptions, past energy consumption statistics, monthly energy consumption bills etc. However, there is no feedback on the status of the security and reliability of the dashboard. The presented SGAD has all the above attractive features. In addition, SGAD has the capability to monitor renewable energy generation at consumer sides and utility side, which assists the end-users to take part in market transactions and optimize their energy consumption and energy cost and to avail environmental credit wherever possible. It encourages the end-users by the power market price signals for decisionmaking and intermingles with power generation companies and the power grid.

The dashboard developed by EirGrid plc [27] deals with energy data relevant to their energy groups. It is very general and not user specific. It empowers the users to outlook, parallels their associated power system information, and graphs in one location. In addition, the users can visualize the realtime energy data with the time-varying energy cost. It is userfriendly and with no need for log in. Since there is no need to $\log$ in, the information provided is general and not user

\section{REFERENCES}

[1] G. Andersson, P. Donalek, R. Farmer, N. Hatziargyriou, I. Kamwa, P. Kundur, N. Martins, J. Paserba, P. Pourbeik, J. Sanchez-Gasca, R. Schulz ,A. Stankovic, C. Taylor, V. Vittal, "Causes of the 2003 major grid blackouts in North America and Europe, and recommended means to improve system dynamic performance", IEEE Transactions on Power Systems, Vol. 20, No. 4, pp. 1922-1928, 2005

[2] Litos Strategic Communication, The Smart Grid - an introduction, US Department of Energy, Available at: https://energy.gov/sites/prod/ files/oeprod/DocumentsandMedia/DOE_SG_Book_Single_Pages $\% 281$ $\% 29$.pdf, 2008

[3] Smartwatt, "Implementing Energy Efficient Facility Management", Available at: https://www.smartwatt.com/implementing-energy-efficient -facility-management, 2017

[4] International Energy Agency, World Energy Outlook Database, Available at: www.worldenergyoutlook.org/weo2014/, 2014

[5] World Bank, "Toward a Sustainable Energy Future for All: Directions for the World Bank's Energy Sector", Available at: http://www.worldbank.org/content/dam/Worldbank/document/SDN/ener gy-2013-0281-2.pdf, 2013

[6] B. Asare-Bediako, W. L. Kling, P. F. Ribeiro, "Home energy management systems: Evolution, trends and frameworks," 47th International Universities Power Engineering Conference, 2012

[7] International Energy Agency. Technology Roadmap-Smart Grids by International Energy Agency, Available at: www.iea.org/publications /freepublications/publication/smartgrids_roadmap.pdf, 2014

[8] Don Von Dollen, Report to NIST on the Smart Grid Interoperability Standards Roadmap, Available at: https:/www.nist.gov/sites/default/ files/documents/smartgrid/Report_to_NIST_August10_2.pdf, 2009

[9] NIST, NIST framework and roadmap for Smart Grid interoperability standards, Available at: http://www.nist.gov/public_affairs/releases/ upload/Smartgrid_interoperability_final.pdf, 2010 specific. The proposed admin dashboard is scalable and securable. Only registered users can $\log$ in, hence it assures data protection of its registered users.

\section{CONCLUSIONS}

The conventional power system needs to be informative, innovative, and intelligent by integrating the information and communication technology with its electricity infrastructure. With such expectations, SG comes into existence partially in several parts of the world. Hence, the electric utilities and consumers are aware of information such as the power generation level, power demand, unit energy cost, the planned load shedding, the weather forecast, emission level, any cyber threat etc. on real-time basis. Though this information is very helpful for the consumers, the technological constraints of the $\mathrm{SG}$ and the amount of information often provide incovenient results. Hence, a simple technology enabled utility-consumer interactive information system in the form of a dashboard is presented to cater the needs of the electric consumers. The dashboard provides real-time smart grid operating status, power supply and demand, unit energy cost etc. with the support of cloud services. The experience with this dashboard shows its technical suitability of its use and its userfriendliness. The presented dashboard can be extended to various consumers with additional data such as emission credit, monthly electricity bill visualization, feed-in-tariff information etc.

[10] European Commission, European Smart Grids technology platform: vision and strategy for Europe's electricity networks of future, https://ec.europa.eu/research/energy/pdf/smartgrids_en.pdf, 2006

[11] P. Siano, "Demand response and Smart Grids - a survey", Renewable and Sustainable Energy Reviews, Vol. 30, pp. 461-78, 2014

[12] E. K. Lee, R. Gadh, M. Gerla, "Energy service interface: accessing to customer energy resources for Smart Grid interoperation", IEEE Journal on Selected Areas in Communications, Vol. 31, No. 7, pp. 1195-1204, 2013

[13] A. Sheikhi, M. Rayati, S. Bahrami, A. Mohammad Ranjbar, "Integrated demand side management game in smart energy hubs", IEEE Transactions on Smart Grid, Vol. 6, No. 2, pp. 675-83, 2015

[14] B. Asare-Bediako, W. L. Kling, P.F. Ribeiro, "Home energy management systems: Evolution, trends and frameworks", 47th International Universities Power Engineering Conference, pp. 1-5, 2012

[15] T. Rajeev, S. Ashok, "Dynamic load-shifting program based on a Cloud computing framework to support the integration of renewable energy sources", Applied Energy, Vol. 146, pp. 141- 9, 2015

[16] J. Xu, J. Wang, S. Xie, W. Chen, J-U. Kim, "Study on intrusion detection policy for wireless sensor networks", International Journal of Security Applications, Vol. 7, No. 1, pp. 1-6, 2013

[17] R. Verdone, D. Dardari, G. Mazzini, A. Conti, Wireless sensor and actuator networks: technologies, analysis and design, Cambridge: Academic Press, 2008

[18] M. Jaradat, M. Jarrah, A. Bousselham, Y. Jararweh, M. Al-Ayyoub, "The internet of energy: smart sensor networks and big data management for Smart Grid", Procedia Computer Science, Vol. 56, pp. 592-597, 2015

[19] S. Witt, Data Management and Analytics for Utilities, FC Business Intelligence Ltd, 2014

[20] J. Zhao, F. Wen, Y. Xue, Z. Lin, "Cloud Computing: Implementing an Essential Computing Platform for Future Power Systems", Automation of Electric Power Systems, Vol. 34, No. 15, pp. 1-8, 2010 
[21] D. Wang, Y. Song, Y. Zhu, "Information Platform of Smart Grid Based on Cloud Computing", Automation of Electric Power Systems, Vol. 34, No. 22, pp. 7-12, 2010

[22] W. Overcloys, J. Broberg, R. Buyya, Introduction to Cloud Computing, in Cloud Computing: Principles and Paradigms, Wiley, pp. 1-41, 2011

[23] R. Buyya, C. S. Yeo, S. Venugopal, J. Broberg, I. Brandic, "Cloud computing and emerging IT platforms: Vision, hype, and reality for delivering computing as the 5th utility", Future Generation Computer Systems, Vol. 25, No. 6, pp. 599-616, 2009

[24] A. Lunkeit, J. Großmann, "Authentication on high critical infrastructures using interoperable federated identities", Open Identity Summit, pp. 170-177, 2013

[25] R. Santodomingo, M. Rosinger, M. Uslar, T11.3 Role-based access, anonymization, and security concepts for the comprehensive Smart Grid dashboard system, Available at: https://www.discern.eu/datas/ DISCERN_WP11_D11.3_160203_v3.pdf, 2016

[26] Uttar Gujarat Vij Company Limited (UGVCL), Request for Proposal ForAppointment of Smart Grid Implementing Agencyfor Implementation of Smart Grid Pilot Project, Available at: http://www.ugvcl.com/tender/corporate/2013-14/UGVCL-IT-135SmartGrid/mainpage.htm, 2013

[27] EirGrid Group, Smart Grid Dashboard, http://smartgriddashboard. eirgrid.com

[28] D. W. Cearly, D. M. Smith, Key Attributes Distinguish Cloud Computing Services, Gartner, Stamford, CT, 2009

[29] S. Bera, S. Misra, J. J. P. C. Rodrigues, "Cloud Computing Applications for Smart Grid: A Survey", IEEE Transactions on Parallel and Distributed Systems, Vol. 26, No. 5, pp. 1477-1494, 2015

\section{AUTHORS PROFILE}

P. Naveen was born in Tamil Nadu, India, on January 5, 1980. She completed her Bachelor of Engineering and Master of Engineering in Computer Science from Anna University, Chennai, India and Master of Business Administration from Madurai Kamaraj University, India. She worked as a lecturer in Brunei Darussalam for 4 years and currently she is pursuing her Ph.D. in Electrical and Computer Science Engineering with Curtin University, Sarawak, Malaysia. She has published two research papers in IEEE Transactions and two in other reputed journals and conferences. Her areas of interest include cloud computing, networking, artificial intelligence, and development of application packages in interdisciplinary areas.

Wong Kiing Ing was born in Sarawak, Malaysia in 1975. He received B. Eng. (Hons) degree from the University of Manchester in 1999 and Ph.D. degree from the University of Southampton in 2003. In his Ph.D. program, he investigated the electrical aging phenomena of polyethylene materials using electroluminescence technique. He has successfully measured the phase resolved electroluminescence of polyethylene using a Charge Couple Device (CCD) camera for the first time.

Michael K Danquah is a Chartered Engineer (CEng), a Chartered Scientist (CSci) and a Fellow of the Institution of Chemical Engineers (IChemE), UK. $\mathrm{He}$ is also a Chartered Professional Engineer (CPEng) and a Chartered Member (MIEAust) of Engineers Australia. Professor Danquah is currently a Full Professor in the Department of Chemical Engineering and the Associate Dean (Research \& Development) of the Faculty of Engineering and Science, Curtin University, Malaysia. He previously worked as a Senior Lecturer in the Department of Chemical Engineering and the Principal Research Fellow of the Bio Engineering Laboratory, Monash University, Australia. He completed his Ph.D. in Biochemical Engineering from Monash University after obtaining a BSc. Hons (First Class) Degree in Chemical Engineering from KNUST (Ghana).

Amandeep Sidhu's research has resulted in over 60 publications that have been cited over 450 times till date. He has an H-Index of 12 and an average of 28.80 cites per year. He was awarded the highest Indian diasporic award granted to non-resident Indian citizens by the Government of India for his contributions to academia in January 2014. He is the editor for Data,
Semantics and Cloud Computing subseries of Springer-Verlag. He is also the Editor in Chief of the International Journal of Semantic and Infrastructure Services. He holds a Ph.D. in Computing from La Trobe University during which he developed the world's first Protein Ontology that is now part of National Center for Biomedical Ontologies at National Institute of Health, USA. He received the Research Thesis Merit Citation Award for his Ph.D. thesis in 2008. Prior to joining Curtin Sarawak, he worked at Curtin University's Bentley Campus since 2007. There, in collaboration with Microsoft, he led the development of an HPC \& Cloud Facility for Data Intensive Science Projects. He is the recipient of the Curtin Business School's New Researcher of the Year award for 2007. He is also a Senior Member of IEEE and is actively involved in many IEEE activities in the areas of Bioinformatics, Semantic Web, Data Management and Cloud Computing.

A. Abu-Siada received his B.Sc. and M.Sc. degrees from Ain Shams University, Egypt and the Ph.D. degree from Curtin University, Australia, all in electrical engineering. Currently, he is an associate professor in the Department of Electrical and Computer Engineering at Curtin University. His research interests include power system stability, condition monitoring, power electronics, and power quality. He is the editor-in-chief of the Electrical and Electronic Engineering international journal and a regular reviewer for IEEE Transactions on Dielectrics and Electrical Insulation and IEEE Transactions on Power Electronics. 